\title{
MEU ESPELHO TEM DUAS FACES: UMA ORDENA A PENSAR E A OUTRA A AGIR
}

Recebido em 07.05.2019. Aprovado em 11.06.2019

Avaliado pelo sistema double blind review

\author{
Antônia Márcia Rodrigues Sousa \\ Universidade Federal do Mato Grosso \\ bianapsq@hotmail.com
}

Fabiana Pinto de Almeida Bizarria

Universidade da Integração Internacional da Lusofonia Afro-Brasileira

bianapsq@hotmail.com

\author{
Alexandre Oliveira Lima \\ Universidade da Integração Internacional da Lusofonia Afro-Brasileira \\ bianapsq@hotmail.com
}

\section{Resumo}

Este caso para ensino relata a história de um jovem empreendedor, 35 anos, diretor administrativo do grupo Luciano Feijão, considerado um dos maiores grupos de educação do Estado do Ceará, Brasil. Mesmo com a oportunidade de gerenciar a empresa da família, o empreendedor pedagogo, decidiu alinhar sua vida profissional há duas linhas gerenciais, os negócios da família e a criação de sua empresa, a Livraria Pensar, fundada em 2013, em um Shopping Center na cidade de Sobral, interior do Estado. Em três anos de funcionamento a Livraria teve expansão, com o lançamento da segunda unidade no centro de Sobral. A visibilidade e a alta rentabilidade do negócio tem despertado análises em torno da Livraria tornar-se uma franquia. Nesse sentido, dados foram coletados por meio de entrevista semiestruturada com 0 empreendedor-gestor, a fim de compreender os desafios do empreendimento e as decisões de seu gestor e análise documental. Como caso de ensino, sugere-se sua utilização em curso de graduação em Administração ou áreas afins, especificamente nas disciplinas de Empreendedorismo, Tomada de decisão e Processo decisório. Acredita-se que o caso favorece reflexão sobre a teoria em contextos de prática gerencial, ao passo que favorece compreensão sobre características do empreendedorismo e tomada de decisão em ambiente competitivo, à exemplo do mercado educacional.

Palavras-chaves: Empreendedorismo. Tomada de Decisão. Franquia.

\section{Introdução}

Este caso para ensino apresenta a história de um jovem empreendedor de 35 anos nascido em Sobral, interior do Ceará, conhecido no meio empresarial como Lúcio Feijão, pedagogo, filho dos professores Francisco Luciano Feijão e Liduína Maria Pontes Feijão, fundadores de um dos maiores complexos de educação do Ceará, grupo Luciano Feijão que atua há mais de 40 anos na educação básica e, nos últimos 10 anos, no Ensino Superior, ofertando cursos de graduação e pós-graduação stricto sensu na modalidade de Mestrado Interinstitucional. Para o desenvolvimento do caso foram realizadas visitas para efetivação das entrevistas, bem como para anotações em diário de campo sobre observações e percepções dos pesquisadores. Utilizou-se, também, busca documental em material divulgado na imprensa, em sites, jornais e blogs. 
Primogênito de uma família de três irmãos, todos atuam profissionalmente nas empresas da família. Lúcio Feijão convive desde os primeiros passos com os sabores e dissabores que permeiam a educação, em sintonia com o que Alves (2010. p.24) poetisa: "a educação acontece entre a boca e o ouvido. A mãe canta uma canção de ninar. O nenezinho ouve. E ele, que não sabe o sentido das palavras, compreende o sentido da música". E foi convivendo com a atmosfera educacional que o empreendedor optou pela formação em pedagogia, cuja conclusão oficializou seu ingresso como diretor administrativo do Colégio Luciano Feijão.

Em 2011 decidiu conhecer o universo das franquias no segmento de educação, passando então a analisar a possibilidade de abrir uma franquia de uma renomada rede de entretenimento e cultura do Brasil, mas ao avaliar a aquisição percebeu que não estava realizando suas expectativas como gestor de um negócio que sonhara por tanto tempo.

O estudo sobre franquias no ramo de livrarias fez com que o empreendedor refletisse sobre a criação do seu próprio negócio. Este, fruto de uma ideia em sintonia com uma boa oportunidade, ainda precisava de atenção por parte de Lúcio, no caso, analisar a viabilidade no mercado, bem como a definição de um conceito diferenciado o suficiente para ser competitivo. Diante do desafio posto, a opção foi a de contratar uma consultoria.

A orientação especializada foi essencial para que Lúcio Feijão desse andamento a sua livraria, o que culminou com a inauguração em 2013. A livraria Pensar, situada em espaço estratégico e requintado em um shopping da cidade, agrega uma proposta diferenciada com a reunião de obras clássicas, uma papelaria personalizada e um café.

Seguindo a mensagem do poeta-empreendedor Alves, (2005), no sentido de que se deve alçar vôos altos com asas grandes e corpo leve, sendo o corpo a consciência e as asas a humildade, Lucio Feijão inaugura em 2016 a segunda unidade da Livraria Pensar. Esta amplia seu design para possibilitar reuniões de negócios, bem como para encontros de amigos, comemorações. Além do café ser marca do negócio, adotase o "manjar dos Deuses", bolo feito especialmente para tornar o ambiente agradável fazendo uso de todos os sentidos.

O rápido sucesso do empreendimento despertou atenção de empreendedores de outras regiões e capitais, a exemplo de redes de shopping Centers de Fortaleza, Teresina e Belém do Pará. A visibilidade, no entanto, gerou um dilema para Lúcio Feijão: Permanecer com a livraria Pensar em seu município e Estado de origem? Ou fazer novos investimentos e tornar-se uma franquia com capacidade de expansão em todo território brasileiro?

\section{Ideias surgem, oportunidades aproveitam-se}

Popularmente se atribui a Theodore Roosevelt, estadista norte-americano, vigésimo sexto presidente dos Estados Unidos, a afirmativa de que é melhor arriscar tentando alcançar um triunfo, mesmo expondo-se à derrota, do que formar fila com aqueles pobres de espírito que não gozam muito nem sofrem muito, porque vivem naquela penumbra cinzenta que não conhece nem a vitória nem a derrota. Diante desse espírito, Lúcio Feijão realizou investimento de mais de um milhão de reais na Livraria Pensar, mesmo que o cenário apontasse incertezas em relação ao ramo, haja vista números crescentes de e-books, textbooks no mercado brasileiro.

As dúvidas em relação ao negócio também circulavam entre amigos e familiares do empreendedor. Para tanto, o empreendedor investiu atenção em relação à concorrência digital associada a ausência do hábito de leitura. Como são desafios ao empreendimento, há formação contínua da equipe para que possa minimizar riscos. Transformar a Livraria em espaço multidimensional e atrativo para diversos segmentos tem sido a principal estratégia, resultando, com isso, criação de valor para os clientes. As constantes mudanças do mercado e a prática formativa constante são celebrados na gestão do negócio, como forma de garantir a sobrevivência no mercado.

A análise criteriosa de Lúcio indicava viabilidade em relação à Livraria, à medida que configurava-se como 
uma boa oportunidade de negócio para sua região, no caso, cidade de Sobral, localizada na Região Norte do Ceará, a 235 quilômetros de Fortaleza, tem em seu entorno um universo de 46 (quarenta e seis) municípios que estão ligados diretamente a Sobral por meio dos seus serviços de saúde, cultura e educação. A cidade possui intensa circulação acadêmica em função de importantes instituições de Ensino Superior, como, por exemplo, A Universidade Federal do Ceará - UFC, pública que integra o campus de Sobral; 0 Instituto Superior de Teologia Aplicada - INTA, de caráter privado, a Universidade Estadual do Vale do Acaraú - UVA, pública estadual, e o Instituto Federal do Ceara-IFCE.

Além do movimento de estudantes, o empreendedor considerou a implantação do primeiro shopping na cidade, em 2013, e a flutuação de 10 mil pessoas que passam pela cidade ou para estudo ou para negócio. Lúcio confiou nesse conjunto de fatores favoráveis e implementou sua ideia de negócio.

$\mathrm{O}$ espaço foi desenhado para atender públicos distintos. Foi investido em alta padronização na marca e no atendimento, bem como adquirido uma multiplicidade de obras a fim de atender diferentes perfis e gostos. Além disso, é disponibilizado na livraria espaço para lançamento de novas obras, atividades infantis e uma cozinha goumert, cujo carro chefe é o café como bolo. A Livraria também possui artigos de papelaria e presentes, ou seja, Lúcio buscou fazer da Livraria, um lugar de encontros, entretenimentos e consumo de produtos diversificados.

Com a perspectiva de transformar a Livraria em um lugar de cultura e lazer, em 2014, desenvolveu programação artísticas e culturais e em 2015 formou parcerias com instituições de ensino, ofertando livros didáticos para a educação básica e os livros da bibliografia básica e complementar para o ensino superior. A atratividade de novos clientes e as parcerias são essenciais à identificação de novas oportunidades, bem como análise das necessidades de seu público e do mercado.

\section{Riscos, é preciso administrá-los}

É na formação de parcerias que o empreendedor vislumbra lidar com os riscos de seu negócio. Ampliando as redes, compreende que se pode identificar vantagens e construir estratégias capazes de fortalecer a Livraria. $O$ contato com instituições de ensino, por exemplo, ampliou a possibilidade de redefinição de ideias, análise de outras oportunidades e, assim, novos nichos foram sendo configurados. Ajustes às estratégias iniciais foram sendo necessários. A gestão dos riscos e das novas estratégias receberam atenção do empreendedor, ao passo que sua experiência como gestor educacional potencializou sua capacidade de driblar ameaças à expansão do negócio.

Nesse caminho, uma importante estratégia do gestor foi ouvir seus clientes (atuais e potenciais), tanto no que diz respeito à qualidade de serviços e produtos, como sugestões para ampliar a satisfação dos clientes. Para tanto, pesquisas formais e informais deram ao gestor-empreendedor volume de informações importantes para suas tomadas de decisão, bem como a participação em eventos, feiras sobre produtos e serviços educacionais deram suporte para melhor conhecer o mercado do ponto de vista amplo e prospectivo.

Dentre os conhecimentos adquiridos com clientes e eventos, Lúcio Feijão passou a analisar seus concorrentes, a exemplo da Amazon que, sendo a maior empresa de segmentos de livros digitais no mundo e no Brasil, oferta atualmente mais de 1,4 milhões de livros digitais, além do mercado convencional de livros no formato digital. $O$ crescimento do mercado digital das livrarias também é impactado pelas escolas privadas, que, segundo Correio Braziliense (2015), cerca de $40 \%$ já aderiu ao uso de materiais digitais. Mesmo sendo um cultura emergente, em 2015 o crescimento desse setor chegou a 226\%.

Com base na análise da concorrência digital, mas certo de as informações que possuía indicava viabilidade para seu negócio, assim como a alta rentabilidade da Livraria, fez com que o empreendedor, já reconhecido em seu estado como importante investidor na área de educação, ampliasse o negócio. Com isso, inaugurou a segunda unidade da Livraria. 
Nesse cenário, a ampliação também era demandada por investidores de Shopping Centers, à medida que a procura pelo empreendedor foi sendo intensificada, especialmente por representantes de Fortaleza, Teresina e Belém do Pará. A opção por esses espaços parece, então, uma estratégia viável, ao passo que a região Nordeste registrou em 2015, o segundo maior faturamento dos Shoppings Centers, segundo a Associação Brasileira de Shopping Centers (Abrasce). Tais números revelam que o ingresso de novos empreendimentos nesses espaços comerciais deve apresentar alta capacidade de liquidez.

Com esse panorama, a Livraria Pensar, negócio ainda recente, demonstra promissor desempenho financeiro, boa adesão do público local, importante satisfação em relação aos produtos e serviços que oferece, inovação no que tange à constante diversificação de seu aporte de serviços (a exemplo das programações artísticas e culturais) e atratividade de investidores.

\section{Quebrando as regras}

Na percepção do empreendedor, o acréscimo de riscos à expansão de um negócio ainda em maturação requer uma gestão atenta, criativa e ousada. Lúcio Feijão a realiza em associação com o gerenciamento administrativo do Grupo Luciano Feijão que inclui o colégio Luciano Feijão, Luciano Baby (infantil), a Faculdade Luciano Feijão.

Define que assumir riscos engloba a convivência e a sobrevivência em relação às ameaças. Estas são inevitáveis e devem ser consideradas, ao passo que, para além delas, deve-se equacionar as oportunidades, as condições favoráveis, os recursos atuais e potenciais necessários, especialmente quando se projeta a possibilidade de expansão.

Dessa forma, Lúcio opta por assumir o risco da expansão para outros estados e sua animação se deve ao fato de que o negócio cresceu além do que havia desenhado inicialmente. Como o projeto foi desenvolvido em função de uma demanda local, cidade de porte médio, interior do Ceará, a visibilidade e interesse na expansão foi reconhecido como importante oportunidade para o empreendedor.

A receptividade à ampliação para outros estados se alinha à ideia do que seja um bom empreendedor para Lúcio, pois acredita ser essencial a disposição para tomar decisões, sem hesitações, e associa o sucesso dos empreendimentos à capacidade de decidir. Nesse caminho, é perceptível que Lúcio inclina-se para uma expansão rápida do negócio.

De forma geral, o empreendedor reconhece que seu modelo de negócio apresenta várias possibilidades de replicação, porém seu maior dilema está em permanecer com a Livraria Pensar em seu município e Estado de origem, ou fazer novos investimentos e tornar-se uma franquia com capacidade de expansão em todo território Brasileiro?

\section{NOTAS DE ENSINO:}

\section{Objetivos de ensino}

Espera-se que a leitura, análise e discussão do caso orientem os estudantes nos seguintes temas e propósitos:

1. Possibilitar análise de comportamentos e de características empreendedoras e suas relações com a tomada de decisão, especificamente de uma pequena empresa com alto valor investido.

2. Identificação de oportunidades de negócio, com base na trajetória do empreendedor analisado.

3. Avaliação das oportunidades, com base no espaço geográfico da empresa, nas potencialidades, fragilidades e aspectos estratégicos e competitivos diante da possibilidade de criação de uma franquia.

\section{Fonte de dados}

As informações para construção do caso foram coletadas por meio de entrevistas semiestruturadas com 0 fundador da Livraria Pensar, Francisco Lúcio Feijão, e o gerente da empresa. Para tanto, foram realizadas 
visitas para efetivação das entrevistas, bem como para anotações em diário de campo sobre observações e percepções dos pesquisadores. Utilizou-se, também, busca documental em material divulgado na imprensa, em sites, jornais e blogs.

\section{Relações com os objetivos de um curso ou disciplina}

O caso direciona a encontrar aspectos do empreendedorismo por oportunidade, características da personalidade, atitude e comportamento empreendedor. No processo de tomada de decisão apresenta uma alta racionalidade e, nesse quesito, segue as classificações do processo decisório definido por Simon (1960), onde o empreendedor precisa usar a inteligência, concepção, seleção e implementação.

\section{Dinâmica e agenda para discussão}

Nessa etapa o professor deve orientar os alunos a ler o caso e as sugestões bibliográficas antecipadamente. A proposta é que o caso seja desenvolvido ao longo de pelo menos 3 horas. A figura 1 propõe uma agenda sintetizada para a discussão.

\section{Referências}

ABRASCE. Associação Brasileira de Shopping Centers. Cresce número de franquias em Shopping Centers. Disponível em: http://www.portaldoshopping.com.br/. Acesso em 21 de junho de 2016.

ALVES, R. Ao professor, com meu carinho. São Paulo, Vozes, 2010.

ANSOFF, H. I. Estratégia empresarial. São Paulo: McGraw Hill, 1977.

CARR, J. C.; SEQUEIRA, J. M. Prior family business exposure as intergenerational influence and entrepreneurial intent: A theory of Planned Behavior approach. Journal of Business Research, v. 60, p. 1090-1098, 2007.

CORREIO BRAZILIENSE. Mercado de livros digitais cresce no Brasil e se adapta ao novo formato.

Disponivel em: http://www.correiobraziliense.com.br/app/noticia/diversao-e-

arte/2016/06/13/interna_diversao_arte,536046/quanto-vale-o-e-book.shtml. Acesso em 05 de junho de 2016.

DORNELAS, J. C. A. Empreendedorismo: transformando ideias em negócios. Rio de Janeiro: Campus, 2008.

DRUCKER, P. F. Inovação e espírito empreendedor. São Paulo: Pioneira, 1987.

FILION, L. J. Empreendedorismo: empreendedores e proprietários-gerentes de pequenos negócios. RAUSP, São Paulo, v. 34, n. 2, p. 05-28, abr./jul. 1999.

HISRICH, R. D.; PETERS, M. P. Empreendedorismo. 5. ed. Porto Alegre: Bookman, 2009.

MINELLO, I. F.; SCHERER, L. A. L. A. Comportamento e tipologia do empreendedor diante do insucesso empresarial. Revista Sociais e Humanas, Santa Maria, v. 27, n. 01, jan./abr., 2014.

McCLELLAND, D. C. The achieving society. Princeton, NJ: Van Nostrand, 1961.

ORR, M. G.; THRUSH, R.; PLAUT, D. C. The Theory of Reasoned Action as Parallel Constraint Satisfaction: Towards a Dynamic Computational Model of Health Behavior, PLoS ONE, v. 8, n. 5, 2013.

PINCHOT, G.; PELLMAN, R. Intraempreendedorismo na prática: um guia de inovação nos negócios. Rio de Janeiro: Campus, 2004.

SIMON, H. A. A Capacidade de Decisão e de Liderança. Rio de Janeiro: Editora, Fundo de Cultura, 1972. SHORT, J. C.; DAVID J., KETCHEN, J. R.; CHRISTOPHER, L.; SHOOK, R. D. I. The Concept of Opportunity in Entrepreneurship Research: Past Accomplishments and Future Challenges Journal of Management, $\mathrm{v}$. 36, n. 1, p. 40-65, 2010. 
TIMMONS, J. A.; SPINELLI, S. New venture creation: entrepreneurship for the $21^{\text {st }}$ century. 7th ed. New York: McGraw-Hill//rwin, 2006.

VALADARES, J. L.; EMMENDOERFER, M. L.; ALVES, R. C. M.; MORAIS, M. C. A. O Fenômeno do Empreendedorismo Público: Um Ensaio sobre a Aplicabilidade desse Construto na Administração Pública Brasileira. In: ENCONTRO ANUAL DA ASSOCIAÇÃO NACIONAL DOS PROGRAMAS DE PÓSGRADUAÇÃO EM ADMINISTRAÇÃO, 36., 2012, Rio de Janeiro. Anais... Rio de Janeiro ANPAD, 2012.

\section{Bibliografia Complementar}

ÁRABE, M. P. SPITZECK, H. H. A influência da história de vida na tomada de decisões sustentáveis por lideranças corporativas: um estudo de caso. Rio de Janeiro: XXXVIII EnANPAD, 2014.

BAZERMAN, M. H. Processo Decisório: para cursos de Administração, Economia e MBAs. Rio de Janeiro: Elsevier Editora, 2004.

CARREE, M.; STEL, A. V.; THURIK, R.; WENNEKERS, S. Economic development and business ownership: an analysis using data of 23 OECD countries in the period 1976-1996. Small Business Economics, v. 19, n. 3, p. 271-290, 2002.

CARVALHO, P. M. R. Características e motivações dos empresários: $O$ caso dos fundadores de pequenos negócios na cidade da Guarda. In: ANAIS UNIVERSITÁRIOS, SÉRIE DE CIÊNCIAS SOCIAIS E HUMANAS, 8., 1997, p. 107-136.

CHAN, S. C.; LU, M. T. Understanding internet banking adoption and use behavior: a Hong Kong perspective. Journal of Global Information Management, v. 12, n. 3, p.21-43, 2004.

CHELL, E. Toward researching the "opportunistic entrepreneur": a social constructionist approach and research agenda. European Journal of Work and Organizational Psychology, v. 9, n. 1, p. 63-80, 2000.

CHEN, C. C.; GREENE, P. G.; AND CRICK, A. Does entrepreneurial self-efficacy distinguish entrepreneurs from managers?. Journal of Small Business Venturing, v. 13, n. 4, p. 295-316,1998.

CHENG, M. Y.; CHAN, W. S.; MAHMOOD, A. The effectiveness of entrepreneurship education in Malaysia. Education + Training, v. 51, n. 7, p. 555-566, 2009.

CHIESA, V.; PICCALUGA, A. Exploitation and diffusion of public research: the case of academic spin-off companies in Italy. R\&D Management, v. 30, n. 4, p. 329-339, 2000.

DIÁRIO DO NORDESTE. Livraria Pensar oferta literatura especializada. Disponível em $<$ <ttp://diariodonordeste.verdesmares.com.br/cadernos/regional/livraria-pensar-oferta-literaturaespecializada-1.469389>. Acesso em 13 de julho de 2016.

DITTRICH, A. Análise de consequências como procedimento para decisões éticas. Perspectivas, São Paulo, v. 1, n. 1, p. 44-54, 2010.

EBERLIN, R. J.; TATUM, B. C. Making just decisions: organizational justice, decision-making, and leadership. Management Decision, v. 46, n. 2, pp. 310-329, 2008.

FAYOLLE, A.; GAILLY, B. Using the theory of planned behaviour to assess entrepreneurship teaching programmes. Louvain: CRECIS, 2005. (Working Paper, n. 05).

GOMES, F. A. M.; GOMES, C. F. S.; ALMEIDA, A. T. de. Tomada de Decisão Gerencial: Enfoque Multicritério. São Paulo: Editora Atlas, 2002.

HAMEL, G.; PRAHALAD, C. K. Competindo pelo futuro: estratégicas inovadoras para obter o controle do seu setor e criar os mercados de manhã. Trad. Outras Palavras. Rio de Janeiro: Campus, 1995.

HARTMAN, A. Avaliação da cultura intraempreendedora: desenvolvimento e teste de uma metodologia.

Ponta Grossa, Maio: 2006. 
HOPPEN, N. Resolução de problemas, tomada de decisão e sistemas de informação. Caderno de Administração Geral Programa de Eficácia Gerencial, Porto Alegre, 1992.

HOPPEN, N. Sistemas de Informação no Brasil: uma análise dos artigos científicos dos anos 90. Revista de Administração Contemporânea, v. 2, n.3, p. 151-177, set-dez. 1998.

REGALADO, A. The Power to Decide - What's the point of all that data, anyway? It's to make decisions, MIT Technology Review - Business Data and Decision Making: Business report, Jan. 2014. p. 1-15.

RIZZATTI, G.; DOBES, C. E. I. A complexidade do processo decisório em universidades In: MELO, P. A. de; COLOSSI, N. Cenários da gestão universitária na contemporaneidade. Florianópolis: Insular, 2004. p. 185- 192.

SOBRAL EM REVISTA. Programe-se! Livraria Pensar inaugura sua nova loja em Sobral nesta segundafeira (16). Disponível em < http://sobralemrevista.blogspot.com.br/2016/05/programe-se-livraria-pensarinaugura.html.>Acesso em 01 de julho de 2016.

TACHIZAWA, T. ANDRADE, R. O. B. Gestão de instituições de ensino. 3. ed. Rio de Janeiro: FGV, 2002. TONN, B. E. The Future of Future Decision Making. Futures, v. 35, n. 6, p. 673-688, junho, 2003.

VASCONCELLOS, E.; HENSLEY J. R. Estrutura das organizações: estruturas tradicionais, estruturas para inovação, estrutura matricial. São Paulo: Pioneira, 1991. 